\title{
Model obliczeniowy do analizy naprężeń własnych w układzie powłoka-podłoże podczas nanoszenia powłok metodami termicznymi
}

\section{Numerical model for residual stress analysis in a coating- -substrate system produced by thermal spraying methods}

\section{Streszczenie}

W pracy przedstawiono sposób modelowania naprężeń własnych powstałych w czasie procesów termicznego nakładania powłok $\mathrm{Ti}$ na podłoża $\mathrm{Al}_{2} \mathrm{O}_{3}$ metodą elementów skończonych. Modelowanie podzielono na dwa etapy: 1 - rozwiązanie zagadnienia uderzenia pojedynczej cząstki w podłoże z wykorzystaniem programu MES ANSYS-AUTODYNA, 2 - termomechaniczna, nieliniowa analiza do symulacji procesu natryskiwania przez tworzenie przyrastających podwarstw w czasie (uaktualniana geometria) aż do uzyskania powłoki o określonej grubości i schładzanie całości. Obliczenia wykazały niższy poziom naprężeń własnych przy modelowaniu z przyrastającą powłoką w czasie w porównaniu $z$ modelem jednowarstwowym.

\section{Wstęp}

Metody nakładania termicznego są jednymi z najbardziej uniwersalnych technik nanoszenia materiałów powłokowych na materiał podłoża. Umożliwiają wytwarzanie zarówno warstw metalicznych, ceramicznych, jak i kompozytowych na podłożach metalicznych i ceramicznych. W procesach natryskiwania podgrzane lub zimne cząstki materiału powłokowego wyrzucane są z dużą prędkością w kierunku podłoża. Uderzenie rozpędzonych cząstek w pokrywaną powierzchnię

Dr inż. Jolanta Zimmerman, dr hab. inż. Dariusz Golański, dr inż. Tomasz Chmielewski - Politechnika Warszawska, prof. dr hab. inż. Władysław Włosiński - Instytut Maszyn Przepływowych PAN, Warszawa.

\section{Abstract}

The paper presents the scheme of modeling of residual stresses generated during thermal spraying of metal coatings on ceramic substrates by using finite element method. The modeling was divided into two parts: solution of a problem of a single particle impact into the substrate, and nonlinear, thermo-mechanical analysis of a process of coating growth in time increments with geometry upgrade and subsequent cooling of the produced coating-substrate system. The calculation of temperature field and residual stresses in the developed model has been conducted for $\mathrm{Ti}_{-} \mathrm{Al}_{2} \mathrm{O}_{3}$ system. The results showed lower residual stresses obtained by the created model comparing to a simple one layer model.

powoduje ich deformację, tworzą się wtedy tzw. lamele, które „zakotwiczają się" w podłożu, formując war-

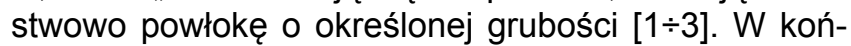
cowym etapie procesu następuje schłodzenie podłoża wraz z utworzoną powłoką do temperatury otoczenia, co wywołuje kolejne naprężenia wynikłe z powodu różnic właściwości cieplnych, fizycznych i mechanicznych materiałów powłoki i podłoża. Stan naprężeń własnych w powłoce i podłożu ma istotny wpływ na ich wytrzymałość, odporność termiczną oraz trwałość zmęczeniową przy cyklicznie zmiennej temperaturze.

Celem pracy była budowa modelu obliczeniowego do oceny rozkładu i wartości naprężeń własnych powstałych w procesie termicznego nakładania powłok na podłoża oraz wyznaczenie tych rozkładów na przykładzie powłoki tytanowej naniesionej na podłożu ceramicznym $\mathrm{Al}_{2} \mathrm{O}_{3}$. 


\section{Założenia do modelowania naprężeń własnych w powłokach nakładanych termicznie}

Proces natryskiwania termicznego składa się z fazy uderzenia cząstek w podłoże oraz powlekania podłoża. Modelowanie stanu naprężeń podzielono więc na dwa etapy. Pierwszy to rozwiązanie zagadnienia uderzenia pojedynczej cząstki w podłoże, z którego pewne wielkości zostaną wprowadzone jako warunki początkowe do drugiego etapu nieliniowej, sprzężonej, termomechanicznej analizy tworzenia przyrastających kolejnych warstw w zadanych odstępstwach czasu (wynikających z warunków procesów) aż do uzyskania powłoki o określonej grubości oraz następnego schładzania powstałego układu powłoka-podłoże.

W procesie budowy modelu obliczeniowego przyjęto następujące założenia:

- Proces osadzania cząstki składa się z uderzenia i powlekania. Czas krzepnięcia kropli jest o dwa rzędy wyższy niż czas deformacji [4], czyli krzepnięcie następuje po deformacji ciekłej kropli i proces ten jest niezależny od procesu krzepnięcia [5]. To założenie rozwiązuje problem dynamiki płynu i pozwala uprościć zagadnienie do zadania termomechanicznego [6].

- Pojedyncza cząstka uderza w podłoże, co powoduje jej znaczną deformację w bardzo krótkim czasie i zamianę znaczącej części energii kinetycznej na ciepło. Cząstki są spłaszczane, tworzą się lamele, co prowadzi do formowania się pojedynczej warstwy, a kolejne warstwy są sukcesywnie dodawane i tak budowana jest powłoka.

- Wszystkie cząstki mają jednakową wstępną temperaturę, a poszczególne warstwy utworzone z cząstek w jednym „przejściu” są równoległe.

- Prędkość natryskiwania jest mniejsza niż prędkość krzepnięcia pojedynczej warstwy, co powoduje, że kolejne cząstki osadzają się na skrzepniętej wcześniej nałożonej warstwie. Podłoże i wcześniej nałożone warstwy modelowane są $w$ stanie stałym $z$ określonym polem temperatury, a właściwości mechaniczne i fizyczne tych materiałów są zależne od temperatury.

- Pomija się wpływ zmian fazowych na wartość naprężeń własnych [7].

- Zakłada się bardzo dobry (idealny) kontakt między podłożem a kolejnymi warstwami.

\section{Modelowanie uderzenia pojedynczej cząstki w podłoże}

Jak wykazano w pracy [3], w czasie lotu cząstek nie zachodzi ich koalescencja i dlatego cząstka może być rozważana jako indywidualna, izolowana od pozostałych. Modelowane jest więc uderzenie pojedynczej cząstki proszku formującego powłokę na podłożu. Dla uproszczenia zadania zostało ono potraktowane jako osiowosymetryczne, co ogranicza rozważania do obciążenia cząstki prędkością prostopadłą do podłoża. Do symulacji numerycznych uderzenia wykorzystano specjalistyczny program ANSYS-AUTODYNA, z analizą dynamiczną typu explicit z kontaktem między stykającymi się powierzchniami oraz z termiczno-mechanicznym sprzężeniem wyników. Mechanizm przepływu ciepła zawiera w modelowaniu przewodzenie cząstki i podłoża. W symulacji numerycznej korzysta się z zasad zachowania: masy, pędu i energii. Obliczenia prowadzone są przy założeniu procesu adiabatycznego.

W rozważanych procesach uderzeniu pojedynczej cząstki towarzyszą duże deformacje oraz duża prędkość odkształcenia cząstki lub podłoża (w zależności od przyjętych rodzajów par łączonych materiałów). Dla materiałów metalicznych przyjęto plastyczny model materiału zdefiniowany przez Johnsona-Cooka [8], który wiąże zredukowane naprężenie plastyczne (wg hipotezy Hubera) jako funkcję zredukowanego odkształcenia plastycznego, bezwymiarowej prędkości płynięcia plastycznego i temperatury. Do opisu właściwości wytrzymałościowych materiałów ceramicznych zastosowano model Johnsona-Holmquista [9].

Uzyskany z rozwiązania zagadnienia uderzenia cząstki w podłoże rozkład temperatury, spowodowany zamianą energii kinetycznej cząstki na energię odkształcenia plastycznego i jej zamianą w energię cieplną, oraz deformacja cząstki (jej spłaszczenie), stały się warunkami początkowymi do przeprowadzenia drugiej fazy symulacji procesu nakładania powłok jako pojedynczych warstewek przyrastających w czasie.

\section{Modelowanie pola temperatury}

W modelowaniu procesu nakładania pojedynczej warstwy powłoki na podłoże przyjęto, że oba elementy są walcowe, co upraszcza zagadnienie do osiowosymetrycznego. Proces modelowania pola temperatury podzielono na kilka etapów, a obliczenia w każdym z nich są oparte na równaniach nieustalonego przepływu ciepła. Warunki brzegowe i początkowe opisano wg następujących założeń:

- Etap 0 - stan wyjściowy, materiał podłoża o zadanych właściwościach fizycznych (zależnych od temperatury) i temperaturze otoczenia $T_{0}$. W określonym krótkim przedziale czasu $t_{0}$ następuje nagrzewanie podłoża od jego górnej, czołowej powierzchni $\mathrm{S}_{1}$ od źródła ciepła, w wyniku temperatury otoczenia $T_{z}$ i wymiany ciepła przez konwekcje $\mathrm{h}_{\mathrm{z}}$ od podmuchu zbliżających się cząstek. Temperatura otoczenia pozostałych powierzchni podłoża równa jest pokojowej $T_{0} \mathrm{z}$ konwekcją swobodną $\mathrm{h}_{0}$.

- Etap 1 - odpowiada czasowi $t_{1}$ od pojawienia się pierwszej warstwy materiału powłoki o temperaturze $T_{c}$ do nadejścia drugiej warstwy. Powierzchnia graniczna między podłożem i pierwszą warstwą powłoki obciążona jest strumieniem cieplnym q działającym $\mathrm{w}$ bardzo krótkim czasie $\mathrm{t}_{\mathrm{z}}$. Wartość $\mathrm{q}$ 
została dobrana tak, aby zapewnić gradient temperatury w podłożu taki jaki otrzymano z rozwiązania zagadnienia uderzenia cząstki w podłoże. Temperatura otoczenia oraz konwekcja pozostają jak w etapie 0.

- Etap $\mathbf{N}$ - po czasie $\mathrm{Nt}_{1}$ pojawia się kolejna warstwa o zadanej temperaturze $\left(T_{c}\right)$ i następuje uzyskanie ostatecznej żądanej grubości powłoki. Warunki brzegowe pozostają bez zmian.

- Etap końcowy - schłodzenie całości do temperatury otoczenia $\mathrm{T}_{0}$.

$\mathrm{Na}$ rysunku 1 zilustrowano uaktualnianą geometrię modelu obliczeniowego oraz warunki brzegowe i początkowe przyjęte do analizy przepływu ciepła podczas formowania powłoki w postaci przyrastających w czasie podwarstw. Rozwiązanie pola temperatury w nakładanych cieplne warstwach przeprowadzono, wykorzystując moduł termiczny programu MES ADINA 8.6. W obliczeniach zastosowano 4-węzłowe osiowosymetryczne elementy przewodzące dla materiału podłoża i powłoki oraz 2-węzłowe elementy konwekcyjne na brzegach. Elementy przewodzące nowoprzybyłej warstwy powłoki oraz elementy konwekcyjne górnej i bocznej powierzchni powłoki są uaktywniane w odstępstwach czasu $t_{1}$, a równocześnie między warstwami dezaktywowane są elementy konwekcyjne. modelowanie pola temperatury w procesie nakładania staje się zagadnieniem z ruchomym warunkiem brzegowym, gdzie zewnętrzna powierzchnia powłoki narasta ze stałą prędkością określoną z prędkości natryskiwania.
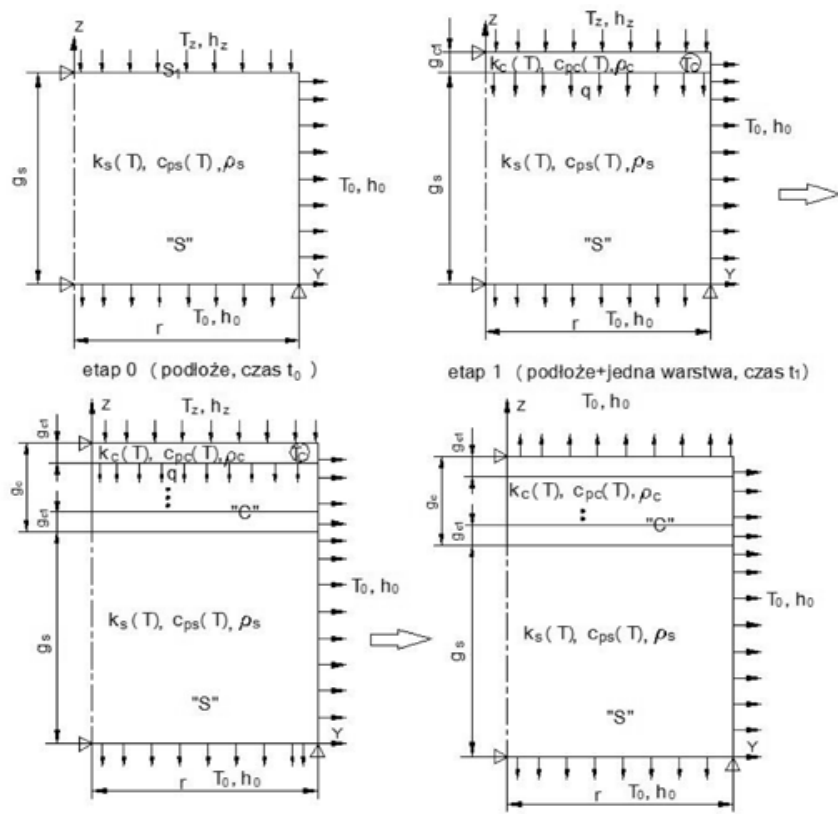

etap 1 (podłoże+jedna warstwa, czas ti) etap 1 ( podłoże +jedna

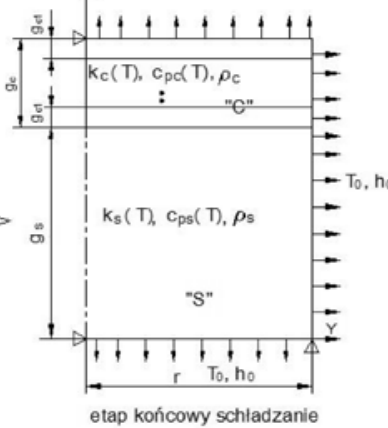

etap $\mathrm{N}$ ( podłoże $+\mathrm{N}$ warstw, czas $\mathrm{Nxt}_{1}$ ) etap końcowy schladzanie $r=13,5 \mathrm{~mm} ; g_{\mathrm{s}}=0,65 \mathrm{~mm} ; \mathrm{g}_{\mathrm{c}}=0,1 \mathrm{~mm} ; \mathrm{g}_{\mathrm{c} 1}=0,02 \mathrm{~mm} ; \mathrm{t}_{1}=0,1 \mathrm{~s} ; \mathrm{Tc}=700 \mathrm{C}$; $h_{z}=100 \mathrm{~W} / \mathrm{m}^{2} \mathrm{~K} ; \mathrm{T}_{0}=25 \mathrm{C} ; \mathrm{h}_{0}=10 \mathrm{~W} / \mathrm{m}^{2} \mathrm{~K} ; \mathrm{t}_{\mathrm{z}}=1 \mu \mathrm{s} ; \mathrm{q}=1700 \mathrm{~W} / \mathrm{m}^{2}$

Rys. 1. Opis warunków brzegowych i początkowych z uaktualnianą geometrią modelu do określenia pola temperatury w powłokach nakładanych termicznie

Fig. 1. Description of the boundary conditions and the initial geometry of the updated reference model to determine the temperature field in the thermally deposited coatings

\section{Modelowanie pola naprężeń}

Pole temperatury jest czynnikiem aktywującym cieplnie proces deformacji mechanicznej. Obciążenie w analizie naprężeń stanowi więc znane pole temperatury otrzymane $z$ rozwiązania zagadnienia nieustalonego przepływu ciepła w kolejnych przyrostach czasu, które jest nakładane na statyczne pole mechaniczne w serii „kroków czasowych”. W modelowaniu założono termosprężyste zachowanie podłoża ceramicznego, a materiały metaliczne opisano modelem termoplastycznym.

\section{Wyniki obliczeń}

\section{Symulacja uderzenia cząstki w podłoże}

Przeprowadzono symulację uderzenia pojedynczej cząstki tytanu w podłoże ceramiczne $\mathrm{Al}_{2} \mathrm{O}_{3}$. Przyjęto temperaturę początkową cząstki Ti i podłoża ceramicznego równą $300 \mathrm{~K}$ oraz prędkość przelotu cząstki Ti $500 \mathrm{~m} / \mathrm{s}$. Założono, że cząstka jest kulista o średnicy $\mathrm{d}=40 \mu \mathrm{m}$, natomiast wymiary podłoża wynoszą 400 x $650 \mu \mathrm{m}$. W czasie uderzenia cząstka uległa spłaszczeniu o ok. $50 \%$ (rys. 2). Do drugiego etapu symulacji przyjęto więc grubość pojedynczej podwarstwy, z której budowana jest powłoka, równą $20 \mu \mathrm{m}$.

Obliczone zmiany temperatury w czasie dla trzech wybranych punktów (nr 1, 29, 2 wg rys. 2) uderzającej cząstki Ti zamieszczono na rysunku 3. Rozkład ten wynika $z$ zamiany energii kinetycznej na energię odkształcenia plastycznego cząstki tytanu i jej zamianę $w$ energię cieplną. Na podstawie rozkładu temperatury oszacowano gradient temperatury wynoszący $22 \mathrm{~K} / \mathrm{mm}$.

W obliczanym w drugiej fazie modelowania polu temperatury, w procesie nakładania powłoki uwzględniono ten wzrost temperatury przez obciążenie czołowej powierzchni granicznej podłoża ceramicznego i powierzchni między pojawiającymi się podwarstwami odpowiednio dobranym strumieniem ciepła (działającym $w$ czasie $t_{z}=1 \mathrm{~ms}$ ), tak aby uzyskać ten sam gradient temperatury. Strumień ten wynosi $1700 \mathrm{~W} / \mathrm{mm}^{2}$.

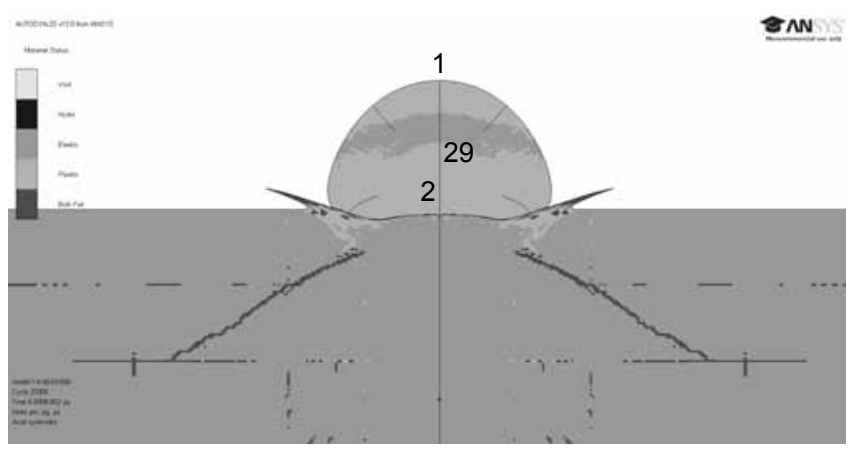

Rys. 2. Deformacja cząstki tytanu po uderzeniu $(v=500 \mathrm{~m} / \mathrm{s})$ w podłoże $\mathrm{Al}_{2} \mathrm{O}_{3}$

Fig. 2. Deformation of titanium particles on impact $(v=500 \mathrm{~m} / \mathrm{s})$ $\mathrm{Al}_{2} \mathrm{O}_{3}$ substrate 


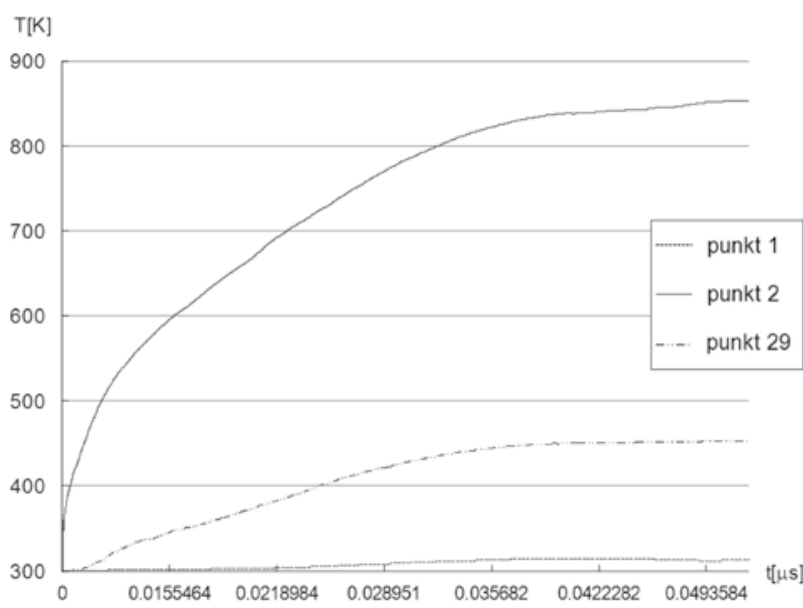

Rys. 3. Rozkład temperatury dla wybranych punktów cząstki Ti w czasie uderzenia w podłoże $\mathrm{Al}_{2} \mathrm{O}_{3}$ wywołany zamianą energii kinetycznej w cieplną

Fig. 3. The temperature distribution at selected points of Ti particles impacting the $\mathrm{Al}_{2} \mathrm{O}_{3}$ substrate induced by the conversion of kinetic energy into heat

\section{Wyniki obliczeń rozkładu temperatury}

$\mathrm{Na}$ rysunku 4 przedstawiono rozkład temperatury w czasie procesu natryskiwania i schładzania układu powłoka-podłoże do temperatury otoczenia w wybranych charakterystycznych punktach leżących $w$ osi próbki. W celu pokazania gwałtownych zmian temperatury, które zachodzą w bardzo krótkim czasie podczas uderzania cząstek Ti w podłoże, zastosowano nierównomierną oś czasu, a czas chłodzenia znacznie skompresowano.

Można zaobserwować, że w podłożu ceramicznym największy gradient temperatury występuje podczas nałożenia pierwszej podwarstwy, przy kolejnych zmniejsza się, a po zakończeniu natryskiwania temperatura na całej grubości jest $w$ przybliżeniu równomierna $\left(T_{B}=190^{\circ} \mathrm{C}, T_{A}=183^{\circ} \mathrm{C}\right)$. Na krzywych temperatury widoczne są dwa piki: pierwszy od energii cieplnej powstałej $z$ energii uderzenia, a drugi od temperatury nowej podwarstwy.

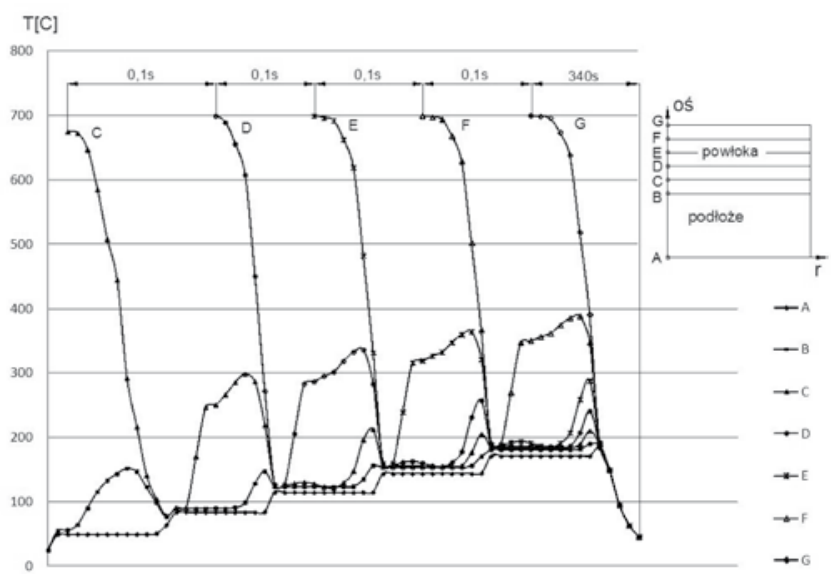

Rys. 4. Rozkłady temperatury w czasie natryskiwania i schładzania w charakterystycznych punktach osi układu powłoka Ti-podłoże $\mathrm{Al}_{2} \mathrm{O}_{3}$ Fig. 4. The temperature history during thermal spraying and cooling

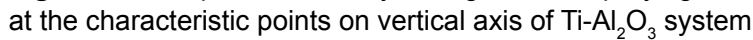

\section{Wyniki obliczeń rozkładu naprężeń i ugięcia układu powłoka-podłoże}

Na rysunku 5 pokazano rozkłady naprężeń składowych w przekroju poprzecznym $\mathrm{Ti}^{-} \mathrm{Al}_{2} \mathrm{O}_{3}$ poprowadzonym wzdłuż osi pionowej układu. W warstwie granicznej od strony ceramiki naprężenia promieniowe osiągają min. $-240 \mathrm{MPa}$ na głębokości $0,02 \mathrm{~mm}$, po czym ich wielkość zmniejsza się liniowo, aż na głębokości $0,42 \mathrm{~mm}$ zmieniają znak na dodatni, osiągając $88 \mathrm{MPa}$ na grubości $0,65 \mathrm{~mm}$. Naprężenia promieniowe w powłoce tytanowej mają charakter rozciągający, a w warstwie granicznej osiągają maks. $260 \mathrm{MPa}$ na głębokości $0,08 \mathrm{~mm}$, po czym ich poziom obniża się, osiągając na brzegu wartość $110 \mathrm{MPa}$. Naprężenia osiowe występują tylko w cienkiej warstwie przygranicznej. Mają one charakter ściskający po stronie ceramiki z min. o wartości -230 MPa na głębokości 0,02 mm i skokowo zmieniają znak na dodatni przy przejściu w powłokę tytanu, osiągając maks $122 \mathrm{MPa}$ na głębokości $0,005 \mathrm{~mm}$ od granicy połączenia.

Zmianę maksymalnego ugięcia w czasie, które występuje w ceramice w punkcie $A$, pokazano na rysunku 6. Po schłodzeniu układu wartość ugięcia wyniosła $0,076 \mathrm{~mm}$. Dokonano porównania linii ugięcia dolnej, czołowej powierzchni ceramiki (p. A) dla jednowarstwowego modelu powłoki (podczas stygnięcia) z modelem powłoki w postaci przyrastających podwarstw (rys. 7).

W przypadku modelu jednowarstwowej powłoki wartość ugięcia była większa o ok. $25 \%$ i wyniosła $0,095 \mathrm{~mm}$. Ma na to wpływ widoczny na rysunku 6 przebieg obciążenia przy modelowaniu powłoki z przyrastającymi warstwami, z której wynikają rozkłady temperatury, naprężeń i deformacji.

$Z$ przeprowadzonych pomiarów ugięcia układu powłoka Ti-podłoże $\mathrm{Al}_{2} \mathrm{O}_{3}$, przeprowadzonych na prostopadłościennym podłożu o wymiarach $20 \times 30 \times 0,65 \mathrm{~mm}$ o grubości powłoki Ti wynoszącym $0,1 \mathrm{~mm}$, otrzymano znacznie niższe wartości ugięcia $(0,012 \mathrm{~mm})$. Świad-

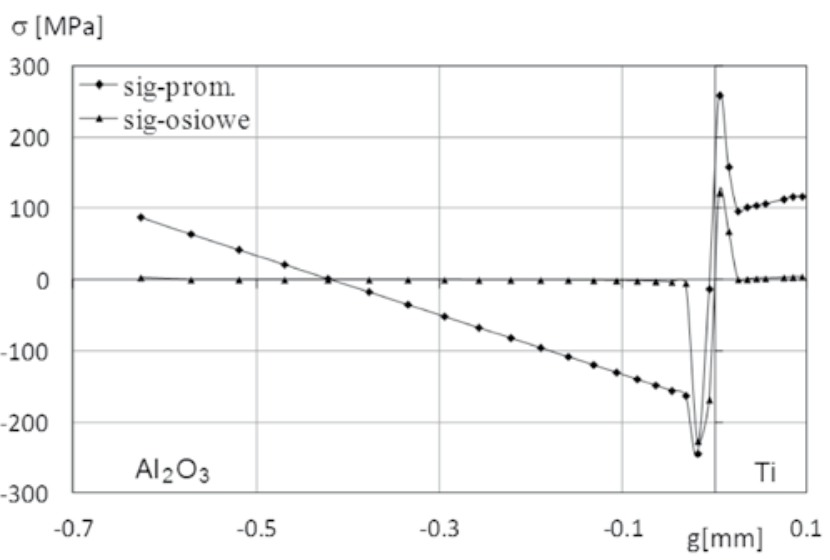

Rys. 5. Rozkłady naprężeń składowych (promieniowych, osiowych) w układzie powłoka Ti-podłoże $\mathrm{Al}_{2} \mathrm{O}_{3}$ w funkcji odległości od granicy $\mathrm{Ti}-\mathrm{Al}_{2} \mathrm{O}_{3}$, po schłodzeniu

Fig. 5. Distributions of stress com-ponents (radial, axial) in a $\mathrm{Ti}-\mathrm{Al}_{2} \mathrm{O}_{3}$ system as a function of the distance from the $\mathrm{Ti}-\mathrm{Al}_{2} \mathrm{O}_{3}$ interface, after cool-ing to room temperature 
czy to o tym, że należy zweryfikować w sposób doświadczalny przyjęte założenia do obliczeń. Mniejsze rozbieżności wyznaczonych ugięć w stosunku do wartości zmierzonych uzyskano dla modelu z przyrostowo uaktualnianą geometrią.

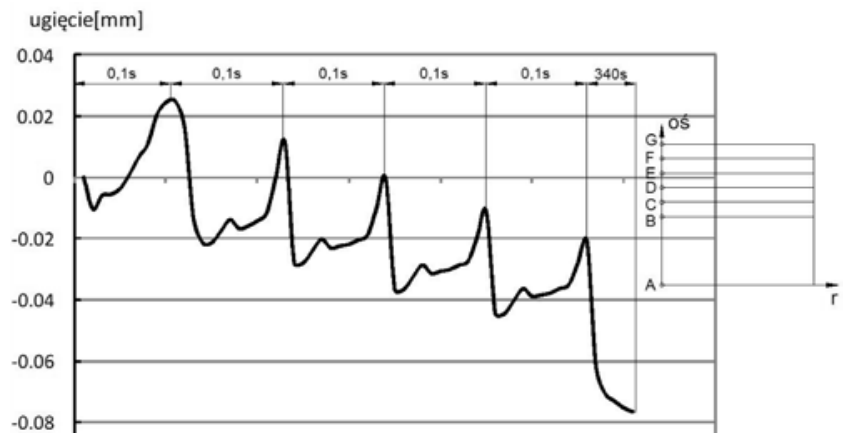

Rys. 6. Zmiana ugięcia w punkcie $A$ w czasie natryskiwania powłoki Ti oraz po schłodzeniu układu $\mathrm{Ti}-\mathrm{Al}_{2} \mathrm{O}_{3}$ do temperatury otoczenia Fig. 6. The deflection of point $\mathrm{A}$ during $\mathrm{Ti}$ coating build-up and after cooling down of $\mathrm{Ti}_{-} \mathrm{Al}_{2} \mathrm{O}_{3}$ system to room tem-perature

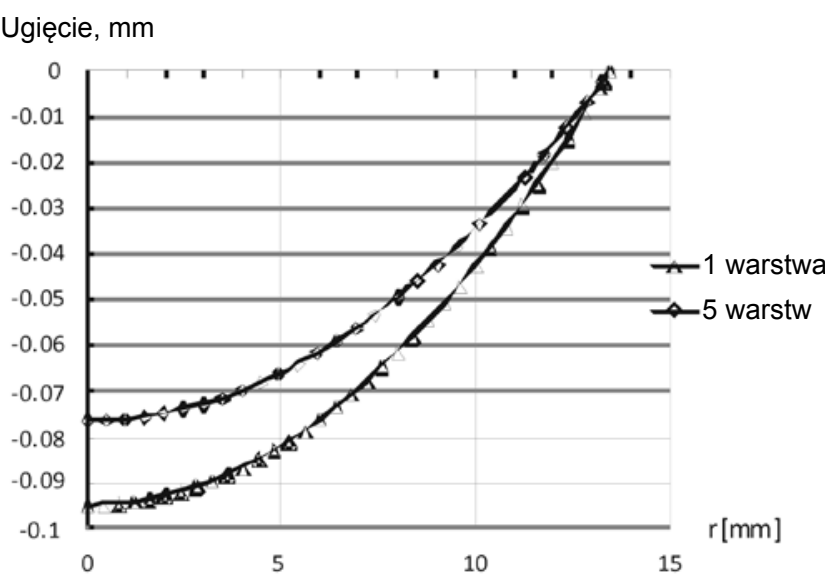

Rys. 7. Porównanie linii ugięcia dolnej, czołowej powierzchni podłoża $\mathrm{Al}_{2} \mathrm{O}_{3}$ w modelu powłoki Ti z przyrastającymi 5 warstwami i modelu jednowarstwowym

Fig. 7. The deflection lines of bottom surface of $\mathrm{Al}_{2} \mathrm{O}_{3}$ substrate for models of Ti coating built-up of 5-sublayers and Ti coating built-up of a single layer

\section{Podsumowanie}

Na podstawie przeprowadzonych obliczeń można wyciągnąć następujące wnioski:

- spłaszczenie pojedynczej cząstki tytanu przy uderzeniu z prędkością v $=500 \mathrm{~m} / \mathrm{s}$ w podłoże $\mathrm{Al}_{2} \mathrm{O}_{3}$ wynosi ok. $50 \%$,

- największy gradient temperatury na grubości ceramiki pojawia się po nałożeniu pierwszej podwarstwy, a po zakończeniu natryskiwania temperatura jest w przybliżeniu równomierna i wynosi ok. $190^{\circ} \mathrm{C}$,

- w obszarze granicy układu $\mathrm{Ti}_{-} \mathrm{Al}_{2} \mathrm{O}_{3}$ od strony ceramiki naprężenia promieniowe są ujemne i osiągają min. $-240 \mathrm{MPa}$ na głębokości $0,02 \mathrm{~mm}$, po czym zmieniają znak na dodatni po stronie tytanu, osiągając poziom $260 \mathrm{MPa}$ na głębokości 0,08 mm,
- naprężenia osiowe są ujemne tylko w warstwie przygranicznej po stronie ceramiki i ich min. wynosi $-230 \mathrm{MPa}$ na głębokości $0,02 \mathrm{~mm}$, po czym skokowo zmieniają znak na dodatni przy przejściu w powłokę tytanu, osiągając maks. $122 \mathrm{MPa}$ na głębokości $0,005 \mathrm{~mm}$,

- modelowanie procesu z przyrastającymi podwarstwami daje niższe końcowe ugięcie układu o ok. $25 \%$ w porównaniu z modelem jednowarstwowym. W dalszym etapie badań należy zweryfikować doświadczalnie przyjęte założenia do obliczeń, m.in. temperaturę powierzchni powłoki, moduł Younga, granicę plastyczności.

\section{Literatura}

[1] Gan Z., Ng H. W.: Deposition-induced residual stress in plasmasprayed coatings, Surf. and Coat. Technol. 187 (2004), s. 307-319.

[2] Stokes J., Looney L.: Residual Stress in HVOF Thermally Sprayed Thick Deposits. ICMCTF 2003.

[3] Li M., Christofides P.: Multi-Scale Modelling and Analysis of an Industrial HVOF Thermal Spray Process, Chem. Eng. Sci. 60 (2005), s. 3649-3669.

[4] Madejski N.J.: Solidification of droplets on a cold surface, Int. J. Heat Mass Transfer, 19 (1976), s. 1009-1013.

[5] Watanabe T., Kuribayashi I., Honda T., Kanzawa A.: Deformation and solidification of a droplet on a cold substrate, Chem. Eng. Sci. 47 (1992), s. 3059-3065.
[6] Amon C. H., Merz R., Prinz F. B., Schmaltz K. S.: Numerical and experimental investigation of interface bonding via substrate melting of an impinging molten metal droplet, Journal of Heat Transfer 118 (1996), s. 164-172.

[7] Zhang X.C., Gong J.M., Tu S.T.: Effect of spraying condition and material properties on the residual stress in plasma spraying. J. Mater. Sci. Technol., 20 (2004), s. 149-53.

[8] Johnson G.R.; Cook W.H.: A constitutive model and data for metals subjected to large strains, high strain rates and high, J. Eng. Mater. and Technol., 105 (1), 1983.

[9] Johnson G. R. and Holmquist T. J.: An improved computational constitutive model for brittle materials, High-Pressure Sci. and Technol., American Institute of Physics, 1994.

Praca finansowana z projektu Narodowego Centrum Badań nr N N519 652840 